\title{
Metabolic consequences of antiepileptic drugs
}

\author{
Scott Mintzer
}

Thomas Jefferson University

Follow this and additional works at: https://jdc.jefferson.edu/neurologyfp

Part of the Neurology Commons

Let us know how access to this document benefits you

\section{Recommended Citation}

Mintzer, Scott, "Metabolic consequences of antiepileptic drugs" (2010). Department of

Neurology Faculty Papers. Paper 30.

https://jdc.jefferson.edu/neurologyfp/30

This Article is brought to you for free and open access by the Jefferson Digital Commons. The Jefferson Digital Commons is a service of Thomas Jefferson University's Center for Teaching and Learning (CTL). The Commons is a showcase for Jefferson books and journals, peer-reviewed scholarly publications, unique historical collections from the University archives, and teaching tools. The Jefferson Digital Commons allows researchers and interested readers anywhere in the world to learn about and keep up to date with Jefferson scholarship. This article has been accepted for inclusion in Department of Neurology Faculty Papers by an authorized administrator of the Jefferson Digital Commons. For more information, please contact: JeffersonDigitalCommons@jefferson.edu. 


\title{
Metabolic Consequences Of Antiepileptic Drugs
}

\author{
Scott Mintzer, MD
}

Jefferson Comprehensive Epilepsy Center, Department of Neurology, Thomas Jefferson University

900 Walnut Street, Suite 200, Philadelphia, PA 19107

phone: 215-955-1222

fax: 215-955-0606

e-mail: scott.mintzer@jefferson.edu

Dr. Mintzer is supported by the National Institute of Health (K23NS058669) 


\section{Abstract}

Purpose of review: Chemical properties of the widely-used older generation antiepileptic drugs (AEDs) suggest that they might be responsible for a number of medical co-morbidities.

Recent findings: AEDs which induce the cytochrome P450 system adversely affect bone, lipid, and gonadal steroid metabolism. Specifically, phenytoin (PHT) causes loss of bone mass in women, and both PHT and carbamazepine (CBZ) produce increases in serum lipids and C-reactive protein, as well as decreases in bioactive testosterone in men. Patients treated with inducing AEDs are at increased risk of fracture. Some contradictory data raise the question of whether bone mass is truly related to enzyme induction, and analogously, of whether reductions in testosterone truly account for male sexual dysfunction. Data showing elevations of surrogate cardiovascular and cerebrovascular risk endpoints with epilepsy patients, mostly inducing AED-treated, are consistent and concerning, however. Another older AED, valproate, is associated with the occurrence of polycystic ovary syndrome when used in young adulthood or adolescence.

Summary: Older generation AEDs are associated with a panoply of metabolic abnormalities. While more research is needed to see whether individual drugs are directly tied to specific clinical outcomes (e.g. risk of infarction), extant data are sufficiently concerning to suggest that these drugs may produce significant adverse health consequences. Newer generation AEDs may be preferable. 


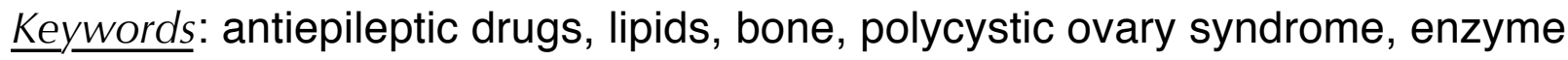
induction 


\section{Introduction}

It is uncommon for a patient to ask of her antihypertensive, antiplatelet agent, or proton pump inhibitor, "What will this medication do to me over the long term?" Yet patients with epilepsy ask this question routinely regarding their antiepileptic therapy, and it seems they have good reason: among the many classes of drugs prescribed for chronic use, antiepileptic drugs (AEDs) appear to have a unique proclivity for affecting metabolism in unanticipated ways. Much of this stems from the property, shared by many AEDs, of altering the effects of enzymes of the cytochrome P450 (CYP450) system. Research over the last two decades has revealed that the CYP450 system plays a prominent role in many metabolic pathways, not just drug metabolism as had initially been believed (and as many physicians still believe). The involvement of the CYP450 system in the metabolism of hormones, vitamins, cholesterol, and other substances forms the scientific underpinning for the empiric observation that many AEDs - especially those which induce the CYP450 system - produce alterations in these pathways, accompanied by additional effects of potential clinical significance.

An understanding of these effects is critical to the optimal care of patients who are treated with these agents, which include not only those with seizures, but also those with essential tremor, migraine, neuralgic pain syndromes, and psychiatric conditions. All of these disorders require long-term - often lifelong - treatment, making the potential slow accretion of metabolic effects a genuine risk. This review is an attempt to provide a capsule summary of the current state of knowledge regarding the metabolic effects of AEDs, highlighting the most recent evidence for clinically-relevant effects and concluding with recommedations for patient care and future research.

\section{Bone and Vitamin D metabolism}

Observations regarding the effects of AEDs on bone mass first surfaced in 
the medical literature four decades ago. The prevailing hypothesis underlying this concern, and the evidence for and against it, were nicely reviewed in a recent manuscript (1). Briefly, the notion is that CYP450-inducing AEDs upregulate the enzymes responsible for the metabolism of vitamin $\mathrm{D}$, leading it to be processed into inactive metabolites. Compensation for this necessitates increased conversation of the major storage form, 5-hydroxyvitamin D (25-OHD), to the active forms. Upregulating this reaction requires increased levels of parathyroid hormone (PTH) as a necessary cofactor. A side consequence of this increase in PTH is an increase in bone turnover, and this "churn" through bone eventually leads to significant loss of bone mass.

A substantial body of evidence indicates that the inducing AEDs are associated with reduced levels of 25-OHD, with the largest amount of evidence impugning carbamazepine (CBZ) $(2-9)(10,11)$ (Table 1). Other studies suggest increases in bone turnover markers in patients treated with the inducers CBZ or phenytoin (PHT), whereas bone turnover appears normal in patients taking the non-inducing drug lamotrigine (LTG) $(6,10)$. A well-done community-based investigation demonstrated rather convincingly that $\mathrm{PHT}$ is associated with accelerated bone loss in elderly women (12), and there is also evidence from case-control studies of increased fracture risk in patients taking inducing AEDs $(13,14)$. Yet not all of the available evidence is consistent with this hypothesis. Studies of patients taking CBZ have yielded mixed results regarding its effects on bone density $(4,15,16)$. In addition, the enzyme-inhibiting drug valproate (VPA) has been implicated as a potential cause of reduced bone density $(15,16)$ and fracture risk $(13,14)$.

Into this breach have stepped a number of recent studies, which unfortunately serve to muddy the waters even further. Pack and colleagues (11) followed women on AED monotherapy with PHT, CBZ, LTG or VPA for a year. They found significant loss of bone at the femoral neck in PHT-treated patients; they also found that reductions in 25-OHD were associated with increases in bone turnover markers, all of which is consistent with the aforementioned prevailing hypothesis. Yet CBZ-treated patients, in whom one would expect similar results, showed no such changes, nor did those on VPA or LTG. This 
study suggests that the effects of individual enzyme-inducing AEDs on bone may differ.

Another noteworthy study in this arena was a large, community-based study of elderly men in whom bone density was measured twice, an average of 4.6 years apart (17). After adjustment for a large number of potential confounders, those taking inducing AEDs had a rate of bone loss no different from controls, whereas those taking non-inducing AEDs had an accelerated rate of bone loss; in fact, this was larger in patients who were being treated at both time points than in patients who were being treated only at one time point, consistent with a dose-response relationship. This surprising result flies in the face of all previous expectations, and while the study appears quite methodologically sound, this author has reservations about its conclusions. One possible source of error concerns the study population: of the patients taking non-inducing AEDs, the vast majority (over $80 \%$ ) were being treated with gabapentin, a drug which is ovewhelmingly prescribed for pain rather than epilepsy in current practice. One wonders if the disease states for which these patients were taking gabapentin might have influenced their bone health relative to controls. Even if one sets aside this caveat, the results should be considered applicable to gabapentin specifically rather than to all non-inducing AEDs.

Another case control study of fracture incidence was recently published, demonstrating that hip fractures were significantly associated with a history of AED use, and that all of this risk accrued with the use of inducing rather than non-inducing AEDs (18). This reconfirms the results of other case-control studies $(13,14)$.

Data on specific newer AEDs is largely lacking, aside from previouslymentioned studies which included LTG $(10,11)$ and one study suggesting that patients treated with oxcarbazepine (OXC) had lower 25-OHD levels and increased bone turnover (6). The latter was replicated in another recent publication, which found that 18 months of OXC treatment in children resulted in higher bone turnover and lower 25-OHD, but no significant change in bone density(19).

Finally, to round out the confusion, one study found that bone density was 
reduced in patients treated with either inducing or non-inducing AEDs but was worse in the former(20). Duration of AED therapy, with any kind of AED, was also associated with greater bone loss. This study is limited by its crosssectional design.

\section{Lipids and other vascular risk markers}

A number of serologic markers which are relevant to cardiovascular risk have been found to be affected by the CYP450-inducing AEDs. These include cholesterol and specific atherogenic lipid fractions (21-23), lipoprotein(a) (23), and homocysteine (24). These alterations suggest that enzyme-inducing AEDs might produce elevations in cardiovascular risk, a notion reinforced by the epidemiologic data, most of which demonstrates that patients with epilepsy suffer from greater vascular mortality and morbidity than the general population $(25-27)(28,29)$ (Table 2). In fact, carotid intima-media thickness, which has proven itself a robust surrogate marker for both cardiovascular and cerebrovascular disease, has been shown to be elevated among epilepsy patients, particularly in those taking inducing AEDs $(30,31)$, supporting the notion that atherosclerosis in increased in this population. Most of these studies are cross-sectional in nature, which limits their ability to inform causative inferences.

One recent investigation directly examined the effects of switching from inducing to non-inducing AEDs on vascular risk markers (32). In this study, 34 patients on $\mathrm{CBZ}$ or PHT in monotherapy were crossed over to monotherapy with either LTG or levetiracetam (LEV). Serologic studies, including lipid profiles, lipoprotein(a) $\{\mathrm{Lp}(\mathrm{a})\}$, homocysteine $(\mathrm{HCY})$ and C-reactive protein (CRP) were performed before the switch and then once again 6 weeks after discontinuation of the old drug. Sixteen normal subjects who were not treated with an AED underwent the same serologic studies on two occasions to serve as a control group. After drug switch, the epilepsy patients showed a mean decline of $25 \mathrm{mg} /$ $\mathrm{dL}$ in total cholesterol, mostly in its atherogenic fractions, as well as a decline of nearly a third in CRP. In addition, patients withdrawn from CBZ experienced a 
sharp reduction in $L p(a)$, while those withdrawn from PHT had subsequent reductions in HCY. Whether patients were switched to LTG or LEV had no bearing on the outcome measures, suggesting that CYP450 de-induction was responsible for the observed changes, and that the vascular risk markers in question were likely increased by $\mathrm{CBZ}$ and $\mathrm{PHT}$ to begin with.

Further evidence for increased vascular risk in this population was provided by Tan et al(33), who obtained a series of serologic studies along with carotid intimal-medial thickness measurements in 195 patients with epilepsy and in controls. They found that epilepsy patients had higher levels of total cholesterol, $\mathrm{CRP}$, and HCY, as well as increased carotid intimal-medial thickness, corroborating a likely increased risk of cardiac and cerebral ischemic disease. Multivariate analysis revealed that duration of AED therapy was significantly correlated with carotid thickness. This study is noteworthy because of its large size and its use of a strong and well-validated surrogate measure of vascular disease. An important weakness is that the results were not presented in a way that allows for the specific elucidation of the effects of enzyme inducers, as it appears that a group of patients taking inducers alone were compared with a polytherapy group, many of whom were likely on inducers as well.

Consistent with the two aforementioned studies, Tomoum et al(34) studied 22 children with epilepsy and found that total cholesterol, various lipid fractions, and apolipoprotein Al were elevated in CBZ-treated patients and reduced in VPAtreated patients relative to controls, reinforcing the notion that CYP450 activity is causative of these changes. Carotid intimal-medial thickness was measured as well, but the sample was small and this was not analyzed appropriately.

\section{Reproductive hormones}

Both enzyme inducers and VPA have been implicated in effects on reproductive hormones. Controversy has been present since the first demonstration that VPA is frequently associated with a constellation of symptoms resembling polycystic ovary syndrome (PCOS)(35). Verification of this cross-sectional study would be ideally done by prospectively examining 
either the results of drug switch or the effects of randomized drug assignment. A study of the former type was published not long after the original report, documenting that patients with PCOS who were taking VPA had resolution of all symptoms following switch to LTG, conclusively demonstrating that the drug was causative of the symptoms in these patients(36). Now a study of the latter type has appeared, shedding further light on this assocation(37). A multinational team of investigators randomized a group of epilepsy patients, both newlydiagnosed and refractory, to treatment with either VPA or LTG for a mean of almost a year. Both clinical and endocrinologic evidence of PCOS were significantly more frequent in the patients receiving VPA, but only in women age 25 and younger. This may help to reconcile some of the conflicting evidence and opinion surrounding this issue, and also may provide some support for the use of VPA in women older than 25 , at least when pregnancy is not planned(38).

Reproductive hormone function among men with epilepsy has also been a subject of active investigation, with one study demonstrating that men taking the enzyme-inducing drugs CBZ or PHT had significantly lower testosterone levels and lower sexual function scores than men with epilepsy who were taking LTG or who were untreated (39). In this cohort, testosterone levels and sexual function were significantly correlated, suggesting that $\mathrm{CBZ}$ and $\mathrm{PHT}$ induce testosterone metabolism, leading to clinically-relevant sexual impairment. While this story appears scientifically sound and sensible, conflicting evidence has recently been published (40). The latter investigators performed a similar study of both men with epilepsy and controls, but with the addition of validated measures of depression and anxiety. They confirmed the previous finding that men taking inducing AEDs had lower testosterone levels, but found that virtually all were still above the threshold needed for normal sexual function, and that testosterone levels did not correlate with sexual function scores. These scores were clearly lower in men with epilepsy, but were correlated with depression and anxiety rather than the hormonal measures. The reasons for the discrepancies between this study and previous studies remains unclear, and more work will clearly need to be done to further elucidate these findings. 


\section{Conclusions}

Recent studies have added to the considerable evidence that AEDs, particularly the older-generation agents, may have diffuse and profound effects upon a variety of metabolic pathways. The several discussed here do not include others which are complex enough to engender full-fledged discussions of their own (e.g. drug interactions, teratogenicity). A common thread runs through much of this data: it is clear that enzyme-inducing AEDs produce substantial alterations of a host of serologic parameters, but demonstration of the clinical end effects of those changes remain to be elucidated. Thus, patients with epilepsy are at increased risk for fractures, and PHT and CBZ lower vitamin D levels, but only the former drug has been clearly shown to affect bone density, and it is not clear that reduction in vitamin $D$ is responsible. In a similar vein, patients with epilepsy have significantly higher rates of cardiovascular and cerebrovascular disease, and there is mounting evidence that PHT and CBZ are clearly responsible for elevations of several strong and well-validated vascular surrogate markers, but epidemiologic data to compare the rate of vascular events attributable to specific drugs is lacking.

Another common thread is that the effects of individual drugs may differ; thus, while CBZ and PHT appear to have similar effects on cholesterol, testosterone, and 25-OHD levels, their effects on $\mathrm{Lp}(\mathrm{a})$ and bone density are different. More research is clearly needed to explore the mechanisms underlying these effects.

In addition, further research is needed to fill in these gaps regarding the effects of specific drugs on particular health outcomes (e.g. myocardial infarction, fracture); such studies will be large and challenging epidemiologically and will require independent (not corporate) funding. Equally important will be determination of the other side of the clinical equation: the relative efficacy of the various drugs for seizure prevention. This is all the more relevant given the availability of a whole generation of AEDs, almost all chemically distinct, that likely avoid adverse metabolic effects. Funding for such research should hopefully be readily available in light of the U.S. government's newfound interest in comparative treatment efficacy. Study of this kind is desperately needed in 
the field of epilepsy, where we lack any data to answer one of our most basic practice questions: if a patient is seizure-free on a drug, what is the likelihood that she will remain seizure-free on a different drug?

The latter point is germane to the concluding opinion of this review. The author is already on record with his views regarding the practical import of the manifold metabolic effects elucidated herein $(32,41)$. At the very least, all patients taking an older-generation AED, whether for epilepsy or any other indication, should be aggressively screened for the appropriate clinical consequences; this would include cardiac risk serology for those taking inducers, signs and symptoms of PCOS for women taking VPA, and bone density testing (as well as vigilance against potential drug interactions) in both groups. If metabolic complications are found, they may be treated, but switching to another AED may well be better medical practice, as it might reduce costs, complications, and co-morbidities. In any case, the specter of these potential metabolic complications make it difficult to recommend the use of older AEDs as first-line therapy at the present time, pending better data regarding comparative efficacy. 


\section{Acknowledgements}

Dr. Mintzer has received research funding from Johnson and Johnson, UCB Pharma, Eisai, Ovation, Medtronic and Neuropace. He has functioned as a consultant for Eisai and Sepracor and a speaker for UCB Pharma and Glaxo SmithKline. His research, described herein, was funded by the Epilepsy Foundation though the Edna Flaig Evans Trust. 
Table 1. Studies comparing 25-hydroxyvitamin D levels in carbamazepine-treated patients and in subjects not taking an enzyme-inducing drug

\begin{tabular}{|c|c|c|c|}
\hline Study & CBZ pts & Control pts & $\% \Delta$ from ctrl \\
\hline Pack 2008(11) & 23.4 & $25.2^{*}$ & $-7 \%$ \\
\hline Kim 2007(4) & 23.0 & $33.8^{*}$ & $-32 \%$ \\
\hline Mintzer 2006(6) & 20.4 & 27.5 & $-26 \%$ \\
\hline Pack 2005(10) & 21.0 & $30.0^{*}$ & $-33 \%$ \\
\hline Verrotti 2002(8) & 26.2 & 27.0 & $-3 \%$ \\
\hline Verrotti 2000(9) & 38.7 & 39.0 & $-1 \%$ \\
\hline Lamberg-Allardt & 22.8 & 27.5 & $-17 \%$ \\
\hline 1990(5) & 22.9 & 39.2 & $-42 \%$ \\
\hline Gough 1986(2) & 11.1 & 17.6 & $-37 \%$ \\
\hline Hoikka 1984(3) & 22.9 & 26.2 & $-13 \%$ \\
\hline Tjellesen 1983(7) & & & \\
\hline
\end{tabular}

Controls were untreated with any antiepileptic drugs except for the values marked with an asterisk ${ }^{*}$, which represent lamotrigine-treated control subjects. $C B Z=$ carbamazepine. $\% \Delta$ from ctrl $=$ percentage difference in 25-hydroxyvitamin $\mathrm{D}$ levels in the CBZ-treated group relative to the control group. All values in $\mathrm{ng} / \mathrm{mL}$. 
TABLE 2. Vascular mortality and morbidity in patients with epilepsy, general population studies

\begin{tabular}{|c|c|c|c|}
\hline Mortality Study & $\begin{array}{c}\text { Study size (follow- } \\
\text { up) }\end{array}$ & $\begin{array}{l}\text { Standardized } \\
\text { mortality ratio }\end{array}$ & $\begin{array}{c}95 \% \text { confidence } \\
\text { interval }\end{array}$ \\
\hline Ding et al(25) & 5,114 person-years & $\begin{array}{c}\text { Myocardial infarction: } \\
10.7^{*}\end{array}$ & $5.6-95.3$ \\
\hline Nilsson et al(26) & 53,250 person-years & $\begin{array}{l}\text { Ischemic heart } \\
\text { disease: } \mathbf{2 . 5 *} \\
\text { Cerebrovascular } \\
\text { disease: } \mathbf{5 . 3}^{*}\end{array}$ & $\begin{array}{l}2.3-2.7 \\
4.9-5.8\end{array}$ \\
\hline Cockerell et al(27) & 7,528 person-years & $\begin{array}{l}\text { Ischemic heart } \\
\text { disease: } \mathbf{1 . 2} \\
\text { Cerebrovascular } \\
\text { disease: } \mathbf{3 . 7 ^ { * }}\end{array}$ & $\begin{array}{l}0.7-1.9 \\
2.4-5.4\end{array}$ \\
\hline Annegers et al(28) & $\begin{array}{l}\text { "Approached 10,000 } \\
\text { person-years" }\end{array}$ & $\begin{array}{l}\text { Ischemic heart } \\
\text { disease: } \mathbf{1 . 2} \\
\text { IHD, patients age } \\
25-44: \mathbf{5 . 7} \\
\text { IHD, patients age } \\
45-64: \mathbf{2 . 5}^{*}\end{array}$ & $\begin{array}{l}0.9-1.5 \\
1.8-13.3 \\
1.4-4.1\end{array}$ \\
\hline Morbidity study & $\begin{array}{c}\text { Total epilepsy } \\
\text { population }\end{array}$ & $\begin{array}{c}\text { Morbidity } \\
\text { (prevalence) ratio }\end{array}$ & $\begin{array}{c}95 \% \text { confidence } \\
\text { interval }\end{array}$ \\
\hline Gaitatzis et al(29) & $\mathrm{N}=5843$ & $\begin{array}{c}\text { Ischemic heart } \\
\text { disease: } 1.34^{*} \\
\text { Ischemic heart } \\
\text { disease }(\text { age }<65) \text { : } \\
1.63^{*} \\
\text { Cerebrovascular } \\
\text { disease: } 6.96^{*} \\
\text { Cerebrovasc. Disease } \\
\text { (age <65): } 14.19^{*}\end{array}$ & $\begin{array}{c}1.19-1.5 \\
1.34-1.98 \\
6.38-7.6 \\
12.04-16.73\end{array}$ \\
\hline Annegers et al(28) & $\mathrm{N}=725$ & $\begin{array}{l}\text { Ischemic heart } \\
\text { disease: } 1.63^{*} \\
\text { IHD, idiopathic } \\
\text { epilepsy only: } 1.49^{*}\end{array}$ & $\begin{array}{l}1.2-2.15 \\
1.00-2.15\end{array}$ \\
\hline
\end{tabular}

Data marked with an asterisk ${ }^{*}$ are statistically significant (i.e. the lower limit of the $95 \%$ confidence interval is $\geq 1$ ). IHD: ischemic heart disease. 
1. *Pack AM, Walczak TS. Bone health in women with epilepsy: clinical features and potential mechanisms. Int Rev Neurobiol. 2008;83:305-328.

A thorough review of the evidence and possible basis for bone disease in patients with epilepsy; despite the title, it is equally applicable to men.

2. Gough $H$, Goggin $T$, Bissessar A et al. A comparative study of the relative influence of different anticonvulsant drugs, UV exposure and diet on vitamin D and calcium metabolism in out-patients with epilepsy. Q J Med.

1986;59:569-577.

3. Hoikka V, Alhava EM, Karjalainen P et al. Carbamazepine and bone mineral metabolism. Acta Neurol Scand. 1984;70:77-80.

4. Kim SH, Lee JW, Choi KG et al. A 6-month longitudinal study of bone mineral density with antiepileptic drug monotherapy. Epilepsy Behav. 2007;10:291-295.

5. Lamberg-Allardt C, Wilska M, Saraste KL, Gronlund T. Vitamin D status of ambulatory and nonambulatory mentally retarded children with and without carbamazepine treatment. Ann Nutr Metab. 1990;34:216-220.

6. Mintzer S, Boppana P, Toguri J, DeSantis A. Vitamin D levels and bone turnover in epilepsy patients taking carbamazepine or oxcarbazepine. Epilepsia. 2006;47:510-515.

7. Tjellesen L, Christiansen C. Serum vitamin D metabolites in epileptic patients treated with 2 different anti-convulsants. Acta Neurol Scand. 1982;66:335-341.

8. Verrotti A, Greco R, Latini G et al. Increased bone turnover in prepubertal, pubertal, and postpubertal patients receiving carbamazepine. Epilepsia. 2002;43:1488-1492.

9. Verrotti A, Pascarella R, Trotta D et al. Hyperhomocysteinemia in children treated with sodium valproate and carbamazepine. Epilepsy Research. 2000;41:253-257.

10. Pack AM, Morrell MJ, Marcus $R$ et al. Bone mass and turnover in women with epilepsy on antiepileptic drug monotherapy. Ann Neurol. 2005;57:252-257.

11. **Pack AM, Morrell MJ, Randall A et al. Bone health in young women with epilepsy after one year of antiepileptic drug monotherapy. Neurology. 2008;70:1586-1593.

A longitudinal, controlled investigation of AED effects on bone density and metabolism. This study verifies that phenytoin produces bone loss, and also provides important evidence indicating that its effects differ from those of carbamazepine, despite the fact that both are broad CYP450 enzyme inducers; for example, some support is found for the concept of secondary hyperparathyroidism, but only with phenytoin treatment.

12. Ensrud KE, Walczak TS, Blackwell T et al. Antiepileptic drug use increases rates of bone loss in older women: a prospective study. Neurology. 2004;62:2051-2057.

13. Vestergaard $P$, Rejnmark $L$, Mosekilde $L$. Fracture risk associated with use of antiepileptic drugs. Epilepsia. 2004;45:1330-1337.

14. Souverein PC, Webb DJ, Weil JG et al. Use of antiepileptic drugs and risk of fractures: case-control study among patients with epilepsy. Neurology. 2006;66:1318-1324. 
15. Sheth RD, Wesolowski CA, Jacob JC et al. Effect of carbamazepine and valproate on bone mineral density. J Pediatr. 1995; 127:256-262.

16. Ecevit C, Aydogan A, Kavakli T, Altinoz S. Effect of carbamazepine and valproate on bone mineral density. Pediatr Neurol. 2004;31:279-282.

17. *Ensrud KE, Walczak TS, Blackwell TL et al. Antiepileptic drug use and rates of hip bone loss in older men: a prospective study. Neurology. 2008;71:723-730. A well-done prospective study, suggesting (strangely) that, among elderly men, gabapentin might be more detrimental to bone health than the enzyme-inducing agents.

18. *Tsiropoulos I, Andersen M, Nymark T et al. Exposure to antiepileptic drugs and the risk of hip fracture: a case-control study. Epilepsia. 2008;49:2092-2099. A large study demonstrating elevated fracture risk among AED-treated patients, particularly those treated with enzyme-inducers.

19. Cansu A, Yesilkaya E, Serdaroglu A et al. Evaluation of bone turnover in epileptic children using oxcarbazepine. Pediatr Neurol. 2008;39:266-271.

20. *El-Hajj Fuleihan G, Dib L, Yamout B et al. Predictors of bone density in ambulatory patients on antiepileptic drugs. Bone. 2008;43:149-155.

This study demonstrates reduced bone density among epilepsy patients overall, but especially those on inducing AEDs. Limited by cross-sectional design.

21. Nikolaos T, Stylianos $\mathrm{G}$, Chryssoula $\mathrm{N}$ et al. The effect of long-term antiepileptic treatment on serum cholesterol (TC, HDL, LDL) and triglyceride levels in adult epileptic patients on monotherapy. Medical Science Monitor. 2004;10:MT50-2.

22. Verrotti $A$, Basciani $F$, Domizio $S$ et al. Serum lipids and lipoproteins in patients treated with antiepileptic drugs. Pediatric Neurology. 1998;19:364-367.

23. Bramswig S, Sudhop T, Luers $C$ et al. Lipoprotein(a) concentration increases during treatment with carbamazepine. Epilepsia. 2003;44:457-460.

24. Apeland T, Mansoor MA, Strandjord RE et al. Folate, homocysteine and methionine loading in patients on carbamazepine. Acta Neurol Scand. 2001;103:294-299.

25. Ding $\mathrm{D}$, Wang $\mathrm{W}, \mathrm{Wu} \mathrm{J}$ et al. Premature mortality in people with epilepsy in rural China: a prospective study. Lancet Neurol. 2006;5:823-827.

26. Nilsson L, Tomson T, Farahmand BY et al. Cause-specific mortality in epilepsy: a cohort study of more than 9,000 patients once hospitalized for epilepsy. Epilepsia. 1997;38:1062-1068.

27. Cockerell OC, Johnson AL, Sander JW et al. Mortality from epilepsy: results from a prospective population-based study. Lancet. 1994;344:918-921.

28. Annegers JF, Hauser WA, Shirts SB. Heart disease mortality and morbidity in patients with epilepsy. Epilepsia. 1984;25:699-704.

29. Gaitatzis A, Carroll K, Majeed A, Sander JW. The epidemiology of the comorbidity of epilepsy in the general population. Epilepsia. 2004;45:1613-1622.

30. Schwaninger $M$, Ringleb $P$, Annecke $A$ et al. Elevated plasma concentrations of lipoprotein(a) in medicated epileptic patients. Journal of Neurology. 2000;247:687-690.

31. Hamed SA, Hamed EA, Hamdy R, Nabeshima T. Vascular risk factors and oxidative stress as independent predictors of asymptomatic atherosclerosis in adult patients with epilepsy. Epilepsy Res. 2007;74:183-192. 
32. **Mintzer $\mathrm{S}$, Skidmore $\mathrm{CT}$, Abidin $\mathrm{CJ}$ et al. Effects of antiepileptic drugs on lipids, homocysteine, and C-reactive protein. Ann Neurol. 2009;65:448-456. A longitudinal investigation utilizing a drug-switch paradigm, showing clearly for the first time that lipid levels are elevated with inducing-AED treatment relative to non-inducing $A E D$ treatment. This also is the first study ever to examine CRP in the epilepsy and AED-treated populations, with the finding that this too is elevated by inducing agents. Some differences between the effects of carbamazepine and those of phenytoin emerge.

33. **Tan TY, Lu CH, Chuang HY et al. Long-term antiepileptic drug therapy contributes to the acceleration of atherosclerosis. Epilepsia. 2009;50:1579-1586. This sizable investigation verifies not only elevated lipids, CRP, and homocysteine among epilepsy patients relative to controls, but also carotid intimal thickness, indicating specifically that atherosclerosis appears to be accelerated in this population. Carotid thickness correlates with duration of AED treatment. The study is limited by the lack of drug-specific data.

34. *Tomoum HY, Awadallah MM, Fouad DA, Ali AH. Lipid profile, apolipoproteins A and B in children with epilepsy. J Child Neurol. 2008;23:1275-1281.

One of a number of studies verifying that lipid fractions in children are increased in the setting of carbamazepine treatment and decreased with valproate treatment, consistent with the two drugs' CYP450 effects.

35. Isojarvi JI, Laatikainen TJ, Pakarinen AJ et al. Polycystic ovaries and hyperandrogenism in women taking valproate for epilepsy. N Engl J Med. 1993;329:1383-1388.

36. Isojarvi JI, Rattya J, Myllyla VV et al. Valproate, lamotrigine, and insulinmediated risks in women with epilepsy. Ann Neurol. 1998;43:446-451.

37. $* *$ Morrell MJ, Hayes FJ, Sluss PM et al. Hyperandrogenism, ovulatory dysfunction, and polycystic ovary syndrome with valproate versus lamotrigine. Ann Neurol. 2008;64:200-211.

A large, randomized trial verifying that valproate significantly increases the risk of polycystic ovary syndrome in young women. They also show that this risk appears to be present only when the drug is started before age 26, a clarification that may be of substantial practical benefit, particularly when treating women with generalized epilepsy.

38. Meador $\mathrm{KJ}$, Baker $\mathrm{GA}$, Browning $\mathrm{N}$ et al. Cognitive function at 3 years of age after fetal exposure to antiepileptic drugs. N Engl J Med. 2009;360:1597-1605.

39. Herzog AG, Drislane FW, Schomer DL et al. Differential effects of antiepileptic drugs on sexual function and hormones in men with epilepsy. Neurology. 2005;65:1016-1020.

40. *Talbot JA, Sheldrick R, Caswell H, Duncan S. Sexual function in men with epilepsy: how important is testosterone? Neurology. 2008;70:1346-1352.

Contrasting a previous investigation, this study suggests that the testosterone-reducing effects of enzyme-inducing AEDs are not an important cause of sexual dysfunction among men with epilepsy.

41. *Mintzer S, Mattson R. Should enzyme-inducing antiepileptic drugs be considered first-line agents? Epilepsia. 2009;50:42-50.

A practical debate covering the pros and cons of enzyme-inducing AEDs as first-line epilepsy therapy. 
